\title{
Rate and process of tube production by the deep- sea hydrothermal vent tubeworm Riftia pachyptila
}

\author{
Françoise Gaill $^{1, *}$, Bruce Shillito ${ }^{1}$, Frédéric Ménard ${ }^{1}$, Gérard Goffinet ${ }^{2}$, \\ James J. Childress ${ }^{3}$ \\ 'INSU CNRS Roscoff, UPMC, 7 Quai Saint Bernard, F-75252 Paris Cedex 05, France \\ ${ }^{2}$ Institut de Zoologie. Université de Liège, 22, Quai Van Beneden, B-4020 Liège, Belgium \\ ${ }^{3}$ Department of Biological Sciences and Marine Science Institute, University of California, Santa Barbara, \\ California 93106, USA
}

\begin{abstract}
To understand the tube growth process of Ruftia pachyptila, morphological aspects of worms and their tubes were studied. In parallel, tube secretion experiments were performed on live animals, in pressure aquaria. Dry weights of the secretions, along with their chitin content (a major component of the tube) were used to quantify tube production. Our results show a variation of the gross morphology of the plume and the trunk of $R$. pachyptila during its growth and indicate that vestimentum length and tube diameter could be useful indices of individual and tube sizes of $R$. pachyptila. The presence of clumps of freshly secreted tube material at the base of the exoskeleton as well as the new observation of bifid tubes allow us to propose a model of tube growth at both ends. In this model the tube growth would exhibit a moultıng-like step. Bifid shapes may help in space displacement, and the modification of the positioning in height relative to a vent could be used by an individual to modify its access to vent fluid. Tube growth at the apical end facing the plume has been quantified as a minumal estimate of the rate of tube production. Experiments performed on repressurized worms indicate that $1 \mathrm{~mm}^{2}$ of worm vestimentum area may secrete more than $2 \mu \mathrm{g}$ of dry weight tube material per day, leading to a minimum tube growth rate of $14 \mathrm{~cm} \mathrm{yr}^{-1}$. When compared to other marine ecosystems, it is obvious that chitin production per unit of area of the the vent communities, based on the $R$. pachyptila alone, are the highest recorded and similar values were only recorded in polluted freshwater environments.
\end{abstract}

KEY WORDS: Vestimentiferan - Growth rate Exoskeleton Chitun production

\section{INTRODUCTION}

It has been shown that the rate of growth in length of Riftia pachyptila, the giant hydrothermal vent tubeworm, is extremely fast when compared to growth rates of other marine invertebrates (Lutz et al, 1994). However, little is known about the process of tube growth although it is integral to the growth of the animal. The tube is a good marker of the animal growth rate as its length can be easily estimated in situ from pictures and video observations as well as from measurements on captured worms (Fisher et al. 1988, Fustec et al. 1988, Roux et al. 1989, Tunnicliffe et al.

·E-mail: francoise.gaill@snv.jussıeu.fr
1990). There is a problem, however, in that the body length can be shorter than the tube length (Fisher et al. 1988) and the percentage of tube length occupied by a worm apparently depends on the environmental vent flow (Childress \& Fisher 1992). Such observations suggest that the tube growth rate may be different from that of the worm itself

In contrast with the other known species of vestimentiferans, whose tubes are conical in shape, the tube of Riftia pachyptila is primarily cylindrical, which leads to puzzling questions about its growth process. How does $R$. pachyptila accommodate its growth in width in a cylindrical tube? Does the tube increase in length only at the apical end as assumed by Gardiner \& Jones (1993) or does it grow at both ends? 
To understand the tube growth process we first analyzed morphological aspects of tubes from Riftia pachyptila of various sizes and performed morphometric measurements of the animals' bodies and their corresponding tubes. The presence of clumps of freshly secreted tube material at the base of the tubes as previously reported by Jones (1981) as well as the new observation of bifid tubes lead us to analyse the occurrence of these phenomena in different size classes of tubes. Complementary cytological analyses from the body wall facing these clumps were also made. Together these data allow us to propose a model of tube growth. Our results indicate that the tube grows at both ends.

The tube growth at the apical end facing the plume as a minimal estimate of the rate of tube production has been quantified. Experiments were performed on repressurized worms in order to obtain fresh tube secretions. Our results are the first related to tube production on a daily time scale in contrast to previous estimates involving time scales of several months (Roux et al. 1989, Lutz et al. 1994). Amongst the components of the tube, chitin is an extracellular polysaccharide that is widely encountered in various phyla (Jeuniaux 1963). Thus the amount of chitin secreted in tube production (Gaill 1993) was measured and used as a quantitative measure of the tube secretion in order to compare exoskeleton production from various marine ecosystems.

\section{MATERIAL AND METHODS}

Animal collection. Specimens of Riftia pachyptila used in this study were sampled at $2600 \mathrm{~m}$ depth during the French US HERO cruises and the following US cruises at the $13^{\circ} \mathrm{N}$ and $9^{\circ} \mathrm{N}$ sites on the East Pacific Rise. Sampling was done with the submersibles NAUTILE (HERO I, 1991) and ALVIN (HERO II, 1992, 1994, 1995). Complementary observations were also made during HOT 96 (February and March 1996, same areas). Animals were collected from several areas on a number of different dives and placed in an isothermal box for the trip to the surface.

Measurement of tubes and animals. Measurements (length and diameter) of the different worm parts were made on fixed specimens (10\% neutralized formalin) The trunk length includes the opisthosome part. Moreover, the surface of the vestimentum was calculated assuming the vestimentum is a cylinder with the recorded length and diameter of the vestimentum being the length and diameter of the cylinder. It was not possible to measure all parameters on all specimens as the tubes of several specimens were not available, and the plumes were sometimes grazed by predators. The methods used for analyzing the biomet- ric data are the linear regression model and Spearman's rank correlation coefficient (Sokal \& Rohlf 1995). One-tail and 2-tail comparison tests between means of 2 independent samples or paired samples have been computed assuming a significance level of $p=0.05$.

Bifid tube and distal clump analysis. Observations were made on either chemically fixed animals or fresh ones on board ship. Measurements related to the clumps' distribution were made on a smaller sample population (about 30 tubes of various sizes from 3 to $75 \mathrm{~cm}$ ) which did not allow such precise analysis and only qualitative results are presented.

Cytological analysis. Pieces of animals were fixed as previously described in Gaill \& Hunt (1986), with a $3 \%$ glutaraldehyde buffered solution, post-fixed in a $1 \%$ $\mathrm{OsO}_{4}$ solution, and embedded in Araldite resin. Thin sections were obtained from a Reichert-Jung Ultramicrotome, and stained with uranyl acetate and lead citrate. Observations were carried out on a Zeiss 912 TEM, operating at $80 \mathrm{kV}$

Tube secretion experiments. Tube secretion experiments were done during the HERO II cruise (March 1992). During the submersible ascent, the worms were kept in an isothermal container $\left(4^{\circ} \mathrm{C}\right)$, and were submitted to a $260 \mathrm{~atm}$ decompression in about $2 \mathrm{~h}$. Two worms (P5 and G5) were placed in pressure vessels as soon as they arrived on board the ship. Two days later a third worm (P3) was placed in the same vessel, and was kept there for $3 \mathrm{~d}$, whilst P5 and G5 were kept in the vessel. This meant that P5 and G5 were submitted to a decompression/recompression cycle after $2 \mathrm{~d}$ of the $5 \mathrm{~d}$ experiment. All 3 animals were kept at a pressure of $210 \mathrm{~atm}$ and a temperature of $8^{\circ} \mathrm{C}$, under a continuous, flow-through sea water circulation. Establishing or releasing pressure in the vessel only took a few seconds. Before pressurization, a polyethylene ribbon was inserted in between the worm and its tube (Fig. 1). Immediately after recovery from the pressure vessel, the animals were separated from their tubes. Whilst P5 and P3 appeared to be still alive, G5 was dead. The tubes were cut open in order to separate the tube from the polyethylene sheet on which fresh tube material had been laid by the worms (Fig. 1). Square pieces of polyethylene sheet were cut, their areas measured, and the corresponding fresh tube material was gently scraped off with a scalpel. This material was lyophilized and weighed, prior to biochemical analysis of the protein and chitin contents.

Chitin and protein analysis. These analyses were done as previously described (Shillito et al. 1995a). Pieces of air-dried tubes were carefully washed 3 times in distilled water, dried in vacuo over $\mathrm{NaOH}$, and weighed. After treatment for $4 \mathrm{~h}$ at $20^{\circ} \mathrm{C}$ with $0.5 \mathrm{~N}$ $\mathrm{HCl}$ solution and washing in distilled water, they were dried and subsequently subjected to 2 successive $3 \mathrm{~h}$ 


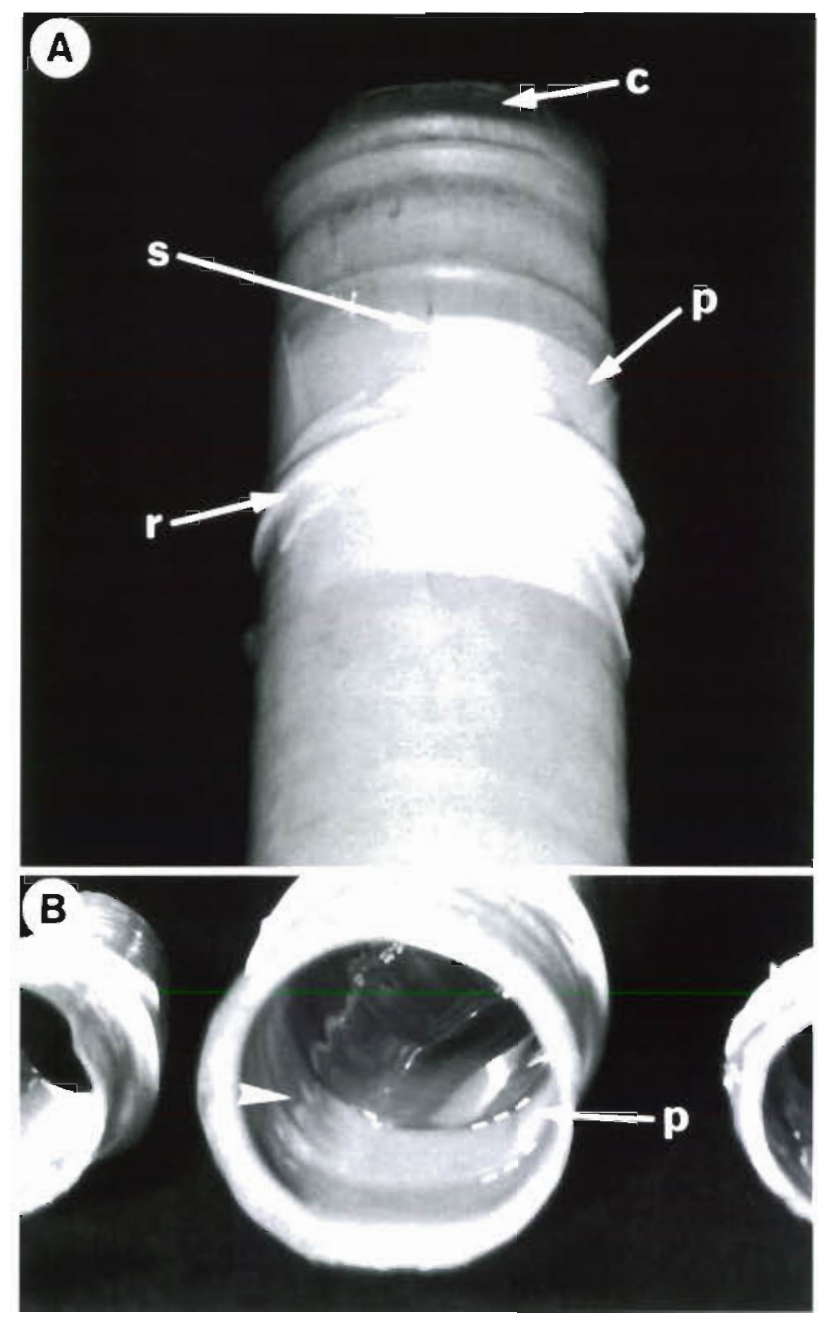

Fig. 1. Riftia pachyptila. Basal extremity of the tube from a repressurized animal (G5), after the tube secretion experiment. Diameter of the tube at the apex is $25 \mathrm{~mm}$. (A) Side-view illustrating the conditioning of the animal. A polyethylene ribbon (p) was inserted through the tube, by 2 diametrically opposite vertical slits (s), at about $3 \mathrm{~cm}$ from the tube apex. Then the 2 emerging extremities of the ribbon were fastened together, and a rubber band ( $r$ ) was tied around the tube, to prevent slipping of the ribbon. Thus, part of the ribbon is in between the animai and its tube (left of the slit), facing the vestimentum region of the worm. When cutting the slits, a stick was used to keep the anmal down in the tube, so that it could not be harmed by the scalpel. At the apex, a gelatinous collar is observed (c), corresponding to freshly laid tube material. (B) Top-view showing the inside of the tube. The polyethylene ribbon ( $p$ ) can still be observed and followed (dotted lines) around the tube, although it is covered by a translucid layer of freshly laid tube material, as witnessed by the shiny aspect of the surface (arrowhead)

treatments with $0.5 \mathrm{~N} \mathrm{NaOH}$ at $100^{\circ} \mathrm{C}$. Proteins were assayed in $\mathrm{NaOH}$ extracts by the Lowry method (Lowry et al. 1951). Chitin was enzymatically assayed in residues, after $\mathrm{HCl}$ and $\mathrm{NaOH}$ extractions, according to Jeuniaux (1963).
Tube production estimation. The tubes were airdried during the cruise. They were later dried for $2 \mathrm{~d}$, at $50^{\circ} \mathrm{C}$, under vacuum, and weighed. In order to com-

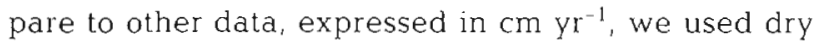
weight and length of each animal's tube to determine linear mass of the tubes. Only the part of the tube occupied by the worm was considered, and it was roughly divided in 5 parts, which were individually weighed. These data provide the relationships between the secreted areas, their weights and their percentages of chitin and protein. On the basis of tube production by the only vestimentum during the experiment, an estimation of annual production was made, assuming that tube secretion had been continuous (see Table 2). The estimated tube production of each individual was compared to its own dried tube weight, considering only the parts of the tubes actually inhabited by the worms (the part situated above the clumps).

\section{RESULTS}

\section{Morphological analysis}

The morphological characteristics of the studied tubeworm population are summarized in Table 1 . Tube sizes are significantly correlated with the total length (Spearman's rank correlation coefficient, $r_{s}=0.91, p<$ $0.001, n=63$ ). Fig. 2 displays the estimated regression equation of tube length (Ltube) as a function of worm length (Ltot), after log transformation of both variables, in order to stabilize the variance $\left(r^{2}=0.922, n=63\right)$. These data show that the tube length is generally greater than the total length of the animal. The maximum tube size is not from the longest animal (Ltot = $32.2 \mathrm{~cm}$ ), although both minima are from the same individual. Four measured specimens present a total

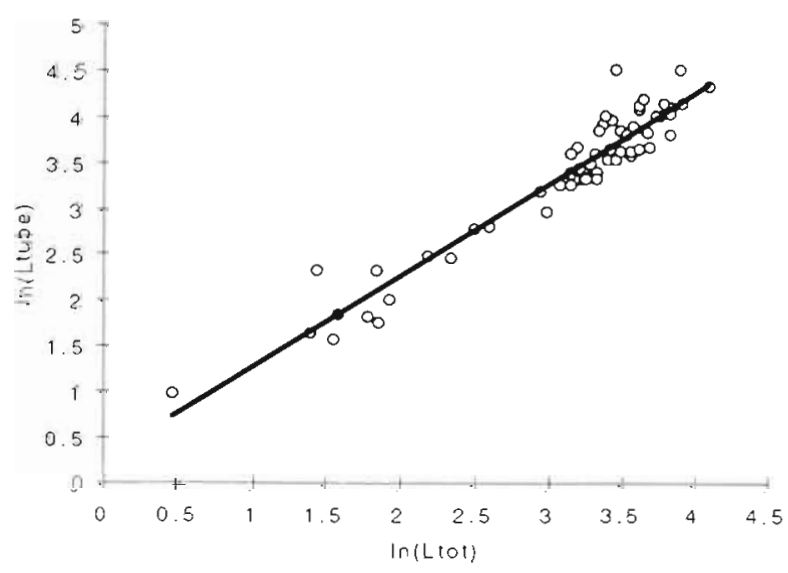

Fig. 2. Riftia pachyptila. Logarithm-transformed relationship between between total body length (Ltot) and total length of the tube (Ltube). $\ln ($ Ltube $)=0.994 \ln ($ Ltot $)+0.295, r^{2}=0.922, n=$ 63, $p<0.001$ ( $n$ : sample size; $r$ Spearman's rank coefficient) 
Table 1 Riftia pachyptıla. Morphological characteristics of the studied tubeworm population. Mean values, standard deviation (SD), minimum and maxımum values were calculated for each characteristic measured in $n$ individuals. Lvest: vestimentum length; Dvest: vestimentum diameter; Dtube: tube diameter at the apex; Svest: vestimentum surface area

\begin{tabular}{|lcrrr|}
\hline Characteristics & Mean & SD & Minimum & Maximum \\
\hline Total length of worm's body: Ltot $(\mathrm{cm})$ & 26.2 & 15.9 & 1.6 & 65.1 \\
Total length of tube: Ltube $(\mathrm{cm})$ & 39.2 & 21.7 & 2.7 & 95.0 \\
Length of plume (\% of total length) & 25.3 & 7.2 & 11.3 & 60.0 \\
Length of vestimentum (\% of total length) & 16.9 & 3.5 & 11.8 & 30.0 \\
Length of trunk (\% of total length) & 57.9 & 8.2 & 10.0 & 71.0 \\
Lvest $(\mathrm{cm})$ & 4.5 & 2.5 & 0.3 & 9.0 \\
Dvest $(\mathrm{cm})$ & 1.5 & 0.7 & 0.15 & 92 \\
Dtube $(\mathrm{cm})$ & 1.7 & 0.7 & 0.2 & 10.9 \\
Svest $\left(\mathrm{cm}^{2}\right)$ & 26.7 & 20.9 & 0.2 & 91 \\
\end{tabular}

length slightly greater than the tube length. However, a 1-tail comparison paired test shows that the mean of the individual size is significantly less than that of the tube length (paired $t$ value $=-9.765, \mathrm{p}<0.001, \mathrm{n}=63$ ).

We observed that the relative proportions of the body vary with worm size (not shown). The relative lengths of the plume and vestimentum tend to decrease as total length increases while trunk length increases at the same time. This is confirmed by the correlations between these parameters $\left(r_{s}\right)$ which are significantly positive for the trunk $\left(r_{s}=0.57, p<0.001\right)$, and significantly negative for the plume $\left(r_{\mathrm{s}}=-0.49, \mathrm{p}<\right.$ $0.001)$ and vestimentum $\left(r_{s}=-0.23, p<0.05\right)$. Thus, shorter worms have a relatively longer plume than larger ones, and larger worms have a relatively longer trunk than shorter ones. To a lesser extent, shorter animals have a longer vestimentum. Complementary analyses have shown greater dispersion for the small sizes $(<10 \mathrm{~cm})$. The same trend is observed when relative lengths are analyzed with the size of the tube.

Table 1 shows that vestimentum length (Lvest) and tube diameter at the apex (Dtube) could be useful indices of individual and tube sizes of Riftia pachyptila. Tube diameters are significantly correlated with the vestimentum diameter (Dvest) $\left(r_{\mathrm{s}}=0.961, \mathrm{p}<0.001, \mathrm{n}=\right.$ 71). We estimated the linear regression equation of Dtube as a function of Dvest $\left(r^{2}=0.948\right)$. The slope $(1.059,95 \%$ confidence interval $= \pm 0.059)$ is significantly greater than $1(p<0.05)$, but both values differ only slightly.

\section{Tube growth process}

Fig 3A illustrates the bifid tube morphology observed over a wide size range of worms ffrom 3 to $75 \mathrm{~cm}$ ) with considerable variation among the worms in the exact morphology. Observations of living tube worms on board ship showed that one part was uninhabited by the worm. The 2 parts were dissimilar in their texture, suggesting that the unoccupied limb was older than the other. The putative older parts were frequently partially dissolved or torn, and quite flimsy in structure as compared to the robust structure of the parts occupied by the worms.

These bifid tubes contain freshly secreted septa both in the older and more recent parts (Fig. 3B). Such septa were also found in non-bifid tubes, however the percentage of septa and length occupied by them were higher in analyzed bifid tubes (data not shown). These septa were found in up to $1 / 3$ of the total tube length (worms collected during 1995). Up to 15 successive septa were found in the basal part of the tube. These septa were variable in number and aspect from one animal to the next. Some septa were gelatinous and translucent whereas others were more solid and firmly stuck to the tube wall. These characteristics were not correlated with tube size, that is, they occurred in small as well as in large worms and seem to be related to the time since secretion.

Cytological analysis of the opisthosome facing these clumps has shown it to contain tube-secretion glands and a high density of the structures involved in chitin secretion. Fig. 3C, D show, at high magnification, the apical border of such cells. Membranous cup-shaped organelles, of around $0.3 \mu \mathrm{m}$ in diameter, are observed, some of them harboring a nascent chitin microfibril (Fig. 3D). These unique and peculiar organelles have been shown to be intimately involved in the chitin synthesis process (Shillito et al. 1993, 1995b). This corroborates the occurrence of tube secretion at the basal part of the worm and identifies the opisthosome as the site of secretion.

\section{Tube secretion experiments}

As described in 'Materials and methods', analyses (Table 2) were performed on the tube secretions produced in the shipboard experiments. The area of the 

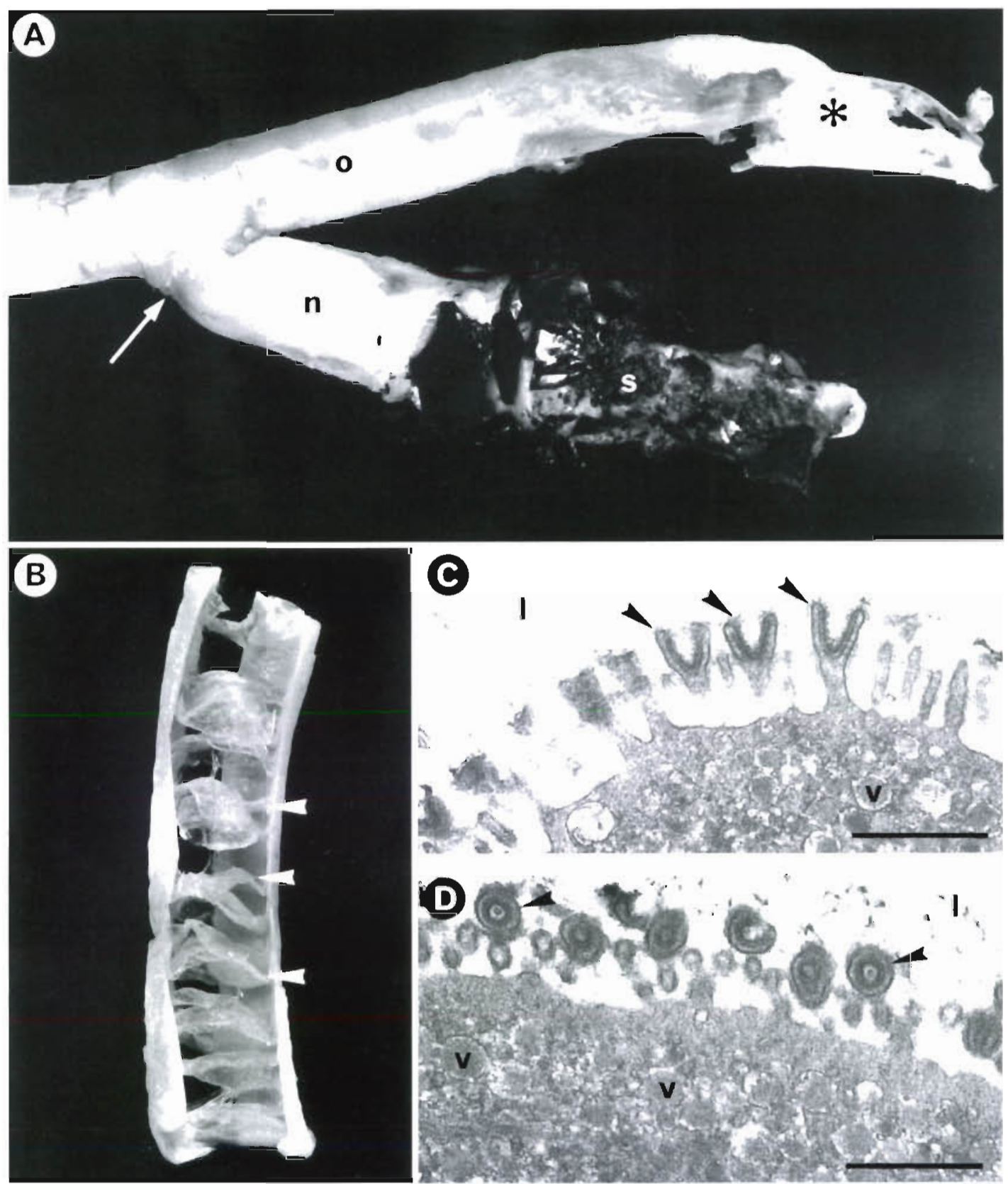

Fig. 3. Riftia pachyptila. Basal part of worm's tube, and ultrastructural observations of opisthosome glandular cells. (A) Basal part of a bifid tube. The tube is about $2 \mathrm{~cm}$ diameter at the point where 1 splits into 2 extensions. One extension (o) is aligned with the tube: the extremity is torn, and appears opaque (:). The second extension ( $\mathrm{n}$ ) points sideways to the tube axis. Black particles from mineral substrate ( $\mathrm{s}$ ) cover the surface of the tube extension. A superficial border between tube and extension is observed (arrow). (B) Section of the basal part of a tube $(2 \mathrm{~cm}$ in diameter), which has been cut open, so to allow observation of the 'clumps' (arrowheads). Clumps appear as a succession of gelatinous translucid sheets. In this case the spacing between clumps is in the 5 to $10 \mathrm{~mm}$ range. (C) and (D) Transmission Electron Microscope (TEM) observations of the apical border of glandulur cells fucing the extracellular lumen (I) in the opisthosome. Numerous vesicles (v) indicate a secretion activity. Longitudinal (C) or transverse (D) sections of cupshaped structures are observed (arrowheads). These structures are identical are responsible for chitin synthesis, a major component of the animal's tube. In (D) a section of a nascent chitin microfibril can be seen inside cup-structure cavities (arrows). Scale bar $=1 \mu \mathrm{m}$

tube where secretion was measured faced the animal's vestimentum. In order to obtain conservative, minimal estimations, our calculation assumes that only the vestimentum is a tube-producing region.
Only the chitin content is indicated in Table 3 . The fresh tube secretion contains about $25 \%$ chitin of dry weight. The protein contents obtained were 45, 50.8, and $39.3 \%$ of dry weight for the P3, P5, and G5 animals 
Table 2. Riftia pachyptila. Tube material freshly secreted during the pressure experiment (fresh tube material: Ftm) was weighed for all 3 individuals and compared to the surface area of the vestimentum. An estimation of a daily or annual production of tube by the vestimentum was obtained, expressed in $\mathrm{mg} \mathrm{d}^{-1}, \mathrm{~g} \mathrm{yr}^{-1}$, or related to the dry weight of each animal's occupied tube (1.89, 4.6 , and $4.87 \mathrm{~g}$ respectively for P3, P5, G5)

\begin{tabular}{|c|c|c|c|}
\hline Sample & P3 & P5 & G5 \\
\hline Calculated vestimentum area $\left(\mathrm{mm}^{2}\right)$ & 1100 & 1410 & 3970 \\
\hline Dry weight of Ftm ( $\mu \mathrm{g} \mathrm{mm}^{-2}$ of vestimentum surface) & 6.41 & 5.21 & 5.31 \\
\hline Theoretical daily production of vestimentum $\left(\mathrm{mg} \mathrm{d}^{-1}\right)$ & 2.35 & 1.47 & 4.22 \\
\hline Theoretical annual production of vestimentum $\left(\mathrm{g} \mathrm{Yr}^{-1}\right)$ & 0.858 & 0.537 & 1.540 \\
\hline Annual vestimentum production in $\%$ of tube dry weight & 45 & 12 & 32 \\
\hline
\end{tabular}

Table 3. Riftia pachyptila. Dry weights and chitin content of fresh tube material (Ftm) facing the vestimentum, for the repressurized animals

\begin{tabular}{|lccc|}
\hline Sample & P3 & P5 & G5 \\
\hline Ftm area $\left(\mathrm{mm}^{2}\right)$ & 195 & 365 & 518 \\
Dry weight of Ftm $(\mathrm{mg})$ & 1.25 & 1.90 & 2.75 \\
Ftm dry weight/area $\left(\mu \mathrm{g} \mathrm{m} \mathrm{mm}^{-2}\right)$ & 6.41 & 5.21 & 5.31 \\
Ftm total production $\left(\mu \mathrm{mm}^{-2} \mathrm{~d}^{-1}\right)$ & 2.14 & 1.04 & 1.06 \\
Chitin (\% of Ftm dry weight) & 24.6 & 23.8 & 28.9 \\
\hline
\end{tabular}

respectively. Our results show that the vestimentum may secrete 1.47 to $4.22 \mathrm{mg}$ of dried tube material in $1 \mathrm{~d}$ (Table 2), leading to an estimate of minimum tube growth rate of up to $14 \mathrm{~cm} \mathrm{yr}^{-1}$ (Table 4). Our values are at the lower limit of other data, but nevertheless quite consistent with the latter, given the facts of the worms being studied after removal from their habitat and our underestimation of the secretory area of these worms

\section{DISCUSSION}

\section{Morphometric measurements}

Our results are similar to those of Fisher et al. (1988). Not surprisingly, a 1 -tailed test shows that the mean of the total length of Fisher's population is significantly greater than our mean $(\mathrm{z}=8.87, \mathrm{p}<0.001)$. A 2 -tailed test between the means of the relative lengths lead to the conclusion that the relative lengths of the vestimentum for both analyzed samples are not significantly different from each other $(|z|=$ $0.108, p>0.05$ ). However, the relative lengths of the plume and of the trunk for the 2 samples are significantly different from each other $(|z|=3.11, \mathrm{p}<$
$0.001 ;$ and $|z|=2.42, p<0.01$, respectively) which results from the influence of the smaller sized individuals present in our sample. This shows a variation of the gross morphology of the plume and the trunk of Riftia pachyptila during its growth.

Smaller animals have a longer plume when compared to larger ones. A long plume length may allow the juvenile to maximize exchange with the environment in order to assure a sufficient supply of nutrients to its symbionts. The relative size of their vestimentum exhibits a higher potential capacity for tube secretion which can enable them to grow faster. Adults have just to support their symbiont populations and to maintain their tube, facts which may explain their relatively longer trunk.

\section{Marker of growth rate}

The apical tube diameter from different vestimentiferan species has been shown to be correlated with the dry (Jollivet 1993) or the fresh (Tunnicliffe 1991) weight of the worms. Our results indicate that vestimentum length and tube diameter could be useful indices of individual and tube sizes of Riftia pachyptila. Because plumes could be abraded, and fragile trunks damaged during sampling, manipulation or preservation, the rigid vestimentum appears to be the most suitable structure upon which to base such an index.

Table 4. Riftia pachyptila. In situ and in vitro growth rate of tubes

\begin{tabular}{|lcl|}
\hline Source & $\begin{array}{c}\text { Reported or estimated } R \text {. pachyptila } \\
\text { tube growth rate }\left(\mathrm{cm} \mathrm{yr}^{-1} \text { ) }\right.\end{array}$ & Location \\
\hline Fustec et al. (1988) & Estimated: 10 to 25 & EPR $13^{\circ} \mathrm{N}$ (Pogosud) \\
Roux et al. (1989) & Estimated: 14 & EPR $13^{\circ} \mathrm{N}$ (Parigo) \\
Lutz et al. (1994) & Reported: 85 & EPR $9^{\circ} \mathrm{N}$ \\
Present study & P3: 14 & EPR $13^{\circ} \mathrm{N}$ \\
& P5: 4 & \\
& G5: 12 & \\
\hline
\end{tabular}




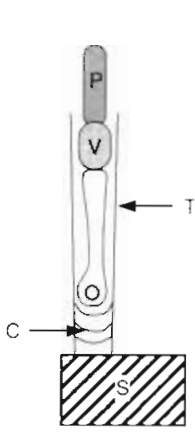

1

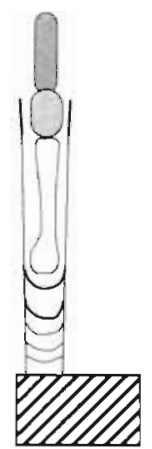

2

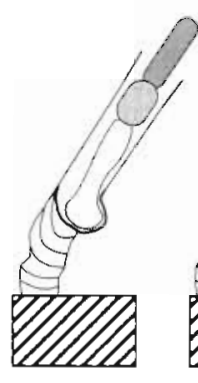

3

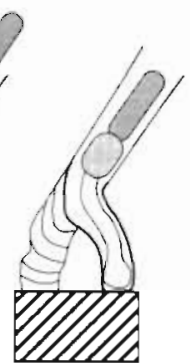

4

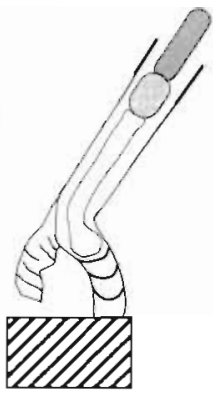

5
Fig. 4. Riftia pachyptila. A model of the worm's growth process. At each step (1 to 5), thick lines represent newly formed tube, with respect to previous step. (1) Schematic representation of the animal in its tube (T), attached to the mineral substrate $(S)$, with the opisthosome $(O)$ resting on a base formed by a series of clumps $(C)$; the vestimentum $(V)$ leveling at the tube apical end, and the plume (P) emerging in the surrounding medium. (2) The worm synthesizes clumps at the basal part of the tube, and also adds tube length at the apical end. At some point, the unoccupied basal part of the tube proves unsufficient to maintain the animal's position (3). This may be due to tube decay (the basal part cannot be renewed, since it is isolated from the worm), to the animal's increasing size, and/or to gradual pressure building up in between neighbouring tubeworms of the same bush. Consequently, the worm starts dissolving its tube, and further synthesizes a new basal tube extension (4), in order to find an anchoring point on the substrate. After this has been achieved, the worm produces new clumps, which allow it to rest further up in its tube, and carry on tube elongation at the apical end (5)

\section{Model of the growth process}

Growth in length and increases in width are 2 ways to solve the problem of reduced space available inside the tube. Based on our data, we propose a model for growth in which these 2 aspects are accounted for (Fig. 4). One way of growing is a 2 step process: first to secrete septa at the basal end which can support the worm and then to produce a new apical end lengthening the tube. We found 1 living sample with a very thin tube wall whose animal was only occupying $1 / 5$ of its tube length $(20 \mathrm{~cm}$ ) (not shown). The other way is a 3 -step process, adding to this operation the dissolution of the tube wall facing the new position of the opisthosome, and the synthesis of a tube base, towards a new anchoring point on the substrate (Fig. 4). Once this is achieved, the animal secretes new septa, so that it rests higher in the tube, in order to carry on with tube apical elongation. We noticed that the worm contraction is such that the worm may shorten by $2 / 3$ of its maximum length. This maximum shortening is higher than the length occupied by the clumps which can reach about $1 / 3$. This indicates that at least half of the old tube part would remain as part of the new tube. Such a modifi- cation would change the worm position relative to its initial one in space. Also, by remodeling the tube base, the animal can adapt it to its increasing size, as opposed to other vestimentiferans, which inhabit conical-shaped tubes (Gardiner \& Jones 1993). Rapid polymerization of the new part would allow a new settlement site relative to the vent. By its weight displacement the old part would fall down.

\section{Space competition to vent access}

Such a growth pattern would also allow adaptation to the fluctuating environment. First, the high growth rate will rapidly modify the position of the worm relative to the vent fluid. Second, Riftia pachyptila are found in clumps where space competition will be important for fluid access, considering the growth rate of these worms. This competition will be more acute as newly settled worms are added to the initial population during the life time of the animals, thus modifying their respective positions relative to the vent source. Bifid shapes may help in space displacement in a crawling-like process. The modification of the positioning in height relative to a vent could be used by an individual to modify its access to vent fluid.

\section{Riftia pachyptila tube growth involves a moulting-like process}

In this model the tube growth would be discontinuous in some way and would exhibit a moulting-like step. This is confirmed by the unoccupied tube fragments which remain attached to the basal parts of the tubes (Fig. 3A). In fact overall tube growth would be discontinuous on the life time scale of the animal but continuous at the time scale of the tube wall formation. It would be different from what occurs in arthropods in that part of the old tube would be conserved by the animal.

The occurrence of bifid tubes indicates that a dissolution process occurs at the basal part, which may involve protease or chitinase secretion by the opisthosome. Twice, a juvenile $(1 \mathrm{~cm}$ in length) was observed orthogonally crossing the tube wall of the adult. Half of the body was in the inner part of the adult tube indicating the ability of the opisthosome to break down the tube material. 
Table 5. Annual chitin production from various marine ecosystems (from Jeuniaux \& Voss-Foucart 1991), as compared to that of a clump of Riftia pachyptila. These data are based on results from Table 4, assuming a density of 178 individuals $\mathrm{m}^{-2}$ as witnessed by Fustec et al. (1988)

\begin{tabular}{|c|c|c|c|c|}
\hline \multirow{2}{*}{$\begin{array}{l}\text { Community } \\
\text { Clumps of vestimentiferans }\end{array}$} & \multicolumn{3}{|c|}{ Chitin production in $\mathrm{g} \mathrm{m}^{-2} \mathrm{yr}^{-1}$} & \multirow{2}{*}{$\begin{array}{c}\text { Ecosystem } \\
\text { Hydrothermal vents }\end{array}$} \\
\hline & $\begin{array}{l}\text { P3 } \\
38\end{array}$ & $\begin{array}{l}\text { P5 } \\
23\end{array}$ & $\begin{array}{l}\text { G5 } \\
79\end{array}$ & \\
\hline Surface zooplankton ${ }^{a}$ & & 1 & & Pelagic \\
\hline Krill ${ }^{\mathrm{b}}$ & & 5.3 & & Pelagic \\
\hline Benthic sessile and vagile biological cover & & 1 & & Benthic \\
\hline Large decapod species & & 6 & & Rocky shores (0 to $200 \mathrm{~m}$ ) \\
\hline
\end{tabular}

\section{Tube growth rate}

In our calculations, only the vestimentum was considered as a tube-producing region, and the trunk and opisthosome regions, although containing significant amounts of tube-producing glands (Shillito et al. 1993), were neglected. Thus, we underestimate the tube production in this respect, as well as in several other ways. First, in our experiments, tube-secretory activity was surely slowed down, in comparison with in vivo conditions. The in situ vent environment exhibited fluctuations (Childress \& Fisher 1992) while conditions prevailing in the experiment $\left(8^{\circ} \mathrm{C}, 210\right.$ atm pressure, $\mathrm{pH} 8.2,200 \mathrm{mM}$ oxygen, and no sulfide) were constant and differed from that of the vent environment. The absence of sulfide for the endosymbionts, the high $\mathrm{pH}$ and the low temperature are not optimal for growth in this species. Second, we underestimate the tube production by considering P5 and G5 over a 5 d period, given that G5 was dead at the end of the experiment, and that both animals had been submitted twice to the stress of decompression (upon in situ collection, and during the pressure experiment).

Previous experiments had shown that Riftia pachyptila specimens could be maintained over $45 \mathrm{~d}$ in pressurized aquaria (Childress et al, 1984). The fact that these animals produce fresh tube during such an experiment indicates that their physiological state is fairly good. This in turn suggests that $R$. pachyptila withstands the collection process, equivalent to a 2 to 3 h 260 atm decompression, reasonably well.

\section{Chitin production in marine ecosystems}

Our data are the first related to tube production involving daily time scales. Previous estimations or reports involve time scales of several months (Roux et al. 1989, Lutz et al. 1994) and therefore deal with growth rates that would be qualified as 'mean' com- pared to our results, which rather represent instantaneous' minimal growth rates. The experimental measurements of minimal growth potential are similar to in situ observations. Underestimations due to experimental conditions and individual variations would explain values lower than those that obtained by Lutz et al. (1994). Complementary experiments will allow us to test this qualitative and quantitative model of growth process.

The chitin and protein content of the fresh tubes were similar to previous data obtained on adult tubes (Shillito et al. 1995a). When compared to other marine ecosystems, it is obvious that chitin production per unit of area of the the vent communities, based on the Riftia pachyptila alone, are the highest recorded. Similar values (51 $\mathrm{g} \mathrm{m}^{-2} \mathrm{yr}^{-1}$ ) are only found in a eutrophic lake in Japan (Yamamoto \& Seki 1979), or in a polluted river (21 $\mathrm{g} \mathrm{m}^{-2} \mathrm{yr}^{-1}$ ) in Belgium (Job 1976) (in this case, exuviae were taken into account). The vent rates approach 100 times those of pelagic or benthic ecosystems: 80 times in our minimal estimations (Table 5) and likely more than 400 times in the work of Lutz et al. (1994).

Acknowledgements. We thank the chief scientists of the different cruises, H. Felbeck, D. Desbruyeres and A. M. Alayse, L. Mullineaux, C. Fisher and the Centob for the collected material, as well as G. Frébourg, M. Zbinden, C. Durif, J. P. Lechaire, E. Thiebaut, M.-F. Voss-Foucart, C. Toussaint, and the CIME Jussieu service, for their technical assistance. This work was funded by the French program DORSALES, the ACR Stress environnementaux (MESR DSPT5/CNRS SDV), IFREMER (URM7) and a DRET grant (no. 95171), and NSF Grant OCE9632861.

\section{LITERATURE CITED}

Childress JJ, Arp AJ, Fischer CR (1984) Metabolic and blood characteristics of the hydrothermal vent tube worm Riftia pachyptila. Mar Biol 83:109-124

Childress JJ, Fisher CR (1992) The biology of hydrothermal vent animals: physiology, biochemistry and autotrophic symbioses. Oceanogr Mar Biol Annu Rev 30:337-441 
Fisher CR, Childress JJ, Arp AJ, Brooks JM, Distel D, Favuzzi JA, Macko SA, Newton A, Powell MA, Somero GN, Soto T (1988) Physiology, morphology, and biochemical composition of Riftia pachyptila at Rose Garden in 1985. Deep Sea Res 35:1745-1758

Fustec A, Desbruyères D, Laubier L (1988) Estimation de la biomasse des peuplements associés aux sources hydrothermales profondes de la dorsale du Pacifique oriental, à $13^{\circ} \mathrm{N}$. Oceanol Acta 8:15-22

Gaill F (1993) Aspects of life development at deep sea hydrothermal vents. FASEB J 7:558-565

Gaill F, Hunt S (1986) Tubes of deep sea hydrothermal vent worms Riftia pachyptila (Vestimentifera) and Alvinella pompejana (Annelida). Mar Ecol Prog Ser 34:267-274

Gardiner SL, Jones ML (1993) Vestimentifera. In: Harrison FW, Rice ME (eds) Microscopic anatomy of invertebrates, Vol 12. Wiley-Liss lnc, New York, p 371-460

Jeuniaux C (1963) Chitine et chitinolyse Masson, Paris

Jeuniaux C, Voss-Foucart MF (1991) Chitin biomass and production in the marine environment. Biochem Syst Ecol 19: $347-356$

Job P (1976) Intervention des populations de Plumatella fungosa (Pallas) (Bryozoaire phylactoleme) dans l'autoépuration des eaux d'un étang et d'un ruisseau. Hydrobiologia $48: 257-261$

Jollivet D (1993) Distribution et évolution de la faune associée aux sources hydrothermales profondes à $13^{\circ} \mathrm{N}$ sur la dorsale du Pacifique oriental: le cas particulier des polychètes Alvinellidae. PhD thesis, Université de Bretagne occidentale, Brest

Jones ML (1981) Riftia pachyptila, new genus, new species, the vestimentiferan worm from the Galapagos Rift geothermal vents (Pogonophora). Proc Biol Soc Wash 93: $1295-1313$

Lowry OH, Rosebrough NJ, Farr AL, Randall RJ (1951) Pro-

This article was submitted to the editor tein measurement with the phenol reagent. J Biol Chem 193:265-275

Lutz R, Shank T, Fornari D, Haymon R, Lilley M, Von Damm K, Desbruyères D (1994) Rapid growth at the deep-sea vents. Nature 371:663-664

Roux M, Rio M, Schein E, Lutz. E, Fritz LW, Ragone LM (1989) Mesures in situ de la croissance des bivalves et des vestimentifères et de la corrosion des coquilles au site hydrothermal de $13^{\circ} \mathrm{N}$ (dorsale du Pacifique oriental). C R Acad Sci 308:121-127

Shillito B, Lechaire JP, Gaill F (1993) Microvilli-like structures secreting chitin crystallites. J Struct Biol 111:59-67

Shillto B, Lechaire JP, Goffinet G, Gaill F (1995a) Composition and morphogenesis of the tubes of vestimentiferan worms. In: Parson LM, Walker CL, Dixon DR (eds) Hydrothermal vent and processes. Geol Soc Sp Pub 87: 295-302

Shillito B, Lübbering B, Lechaire JP, Childress JJ, Gaill F $(1995 b)$ Chitin localization in the secretion system of a repressurized deep-sea tube worm. J Struct Biol 114: $67-75$

Sokal RR, Rohlf FJ (1995) Biometry. WH Freeman and Company, New York

Tunnicliffe $V$ (1991) The biology of hydrothermal vents: ecology and evolution. Oceanogr Mar Biol Annu Rev 29: $319-417$

Tunnicliffe V, Garrett JF, Johnson HP (1990) Physical and biological factors affecting the behaviour and mortality of hydrothermal vent tubeworms (vestimentiferans). Deep Sea Res 37:103-125

Yamamoto H. Seki H (1979) Impact of nutrient in a water chestnut ecosystem at Takahama-Iri Bay of Lake Kasumigawa, Japan. In: McCormac BM (ed) Water air soll pollution, Vol 12. D Reidel Publishing Company, Dordrecht, p 519-527

Manuscript first received: October 9, 1996

Revised version accepted: November 29, 1996 